\title{
Bilgisayar Donanım Öğretimi için Artırılmış Gerçeklik Materyalinin Geliştirilmesi ve Etkililiğinin İncelenmesi
}

\author{
Kağan GÜL ${ }^{1}$, Sami ŞAHİN ${ }^{2}$ \\ ${ }^{1}$ Bilgisayar Sistemleri Öğretmenliği, Süleyman Demirel Üniversitesi, Ankara, Türkiye \\ ${ }^{2}$ Bilgisayar ve Öğretim Teknolojileri Eğitimi Bölümü, Gazi Üniversitesi, Türkiye \\ kagangul@hotmail.com, sami@gazi.edu.tr \\ (Geliş/Received:03.01.2017; Kabul/Accepted:20.09.2017) \\ DOI: $10.17671 /$ gazibtd.347604
}

\begin{abstract}
Özet- $\mathrm{Bu}$ araştırmanın amacı artırılmış gerçeklik (AG) kullanımının bilgisayar donanım öğretiminde başarı üzerine etkisini test etmek ve öğrencilerin ve eğitmenlerin görüşlerini incelemektir. Bu amaç doğrultusunda bilgisayar donanım öğretiminde kullanılmak üzere AG materyalleri geliştirilmiştir. Araştırmanın örneklemi bilgisayar programcılığı bölümünde okumakta olan 122 öğrenciden oluşmuştur. Araştırmada nicel veriler başarı testi ve AG görüş anketi ile nitel veriler ise öğrenciler ve eğitmenler ile görüşmeler yapılarak toplanmıştır. Sonuç olarak AG kullanılan deney grubu öğrencilerinin başarıları karşıllaştırma grubu öğrencilerinin başarılarından anlamlı olarak daha yüksek bulunmuştur. AG öğrenme materyalini kullanan deney grubu öğrencilerinin AG kullanımına yönelik ilgi, kaygı ve memnuniyet durumlarını belirlemek amacıyla yapılan AG görüş anketinden elde edilen verilerin olumlu yönde olduğu sonucuna ulaşılmıştır. Aynı zamanda öğrenciler ile yapılan görüşmelerden elde edilen bulgular da öğrencilerin AG kullanımını genel olarak olumlu bulduklarını göstermiştir.
\end{abstract}

Anahtar Kelimeler - Artırılmış gerçeklik, bilgisayar donanım öğretimi

\section{Development of Augmented Reality Materials and Examination of Efficacy for Computer Hardware Education}

\begin{abstract}
The aim of this study is to test the effect of the use of Augmented Reality (AR) learning material on success in computer hardware instruction and to examine the views of students and instructors on AR usage. For this purpose, learning material was developed to use in computer hardware instruction. The research sample consisted of 122 students who are studying in computer programmer. In this study quantitative data were collected by the achievement test and AR survey while the data were qualitative by means of interviews with students and instructors. According to results obtained from research, the success of the students in experimental group using AR learning material is significantly higher than the success of the students in comparison group. It was concluded that the data obtained from the AR opinion survey conducted to determine the interest, anxiety and satisfaction levels of the AR students in the experimental group using AR learning material were positive. Also, findings obtained from interview with students showed that students generally feel positive about AR usage.
\end{abstract}

Keywords - Augmented reality, AR learning material

\section{GİRIŞ (INTRODUCTION)}

Teknolojik gelişmeler insanların yaşamını önemli ölçüde etkilemekte [1] ve bilişim teknolojileri ile insanlar her türlü bilgiye erişebilme gücüne sahip olmaktadırlar. $\mathrm{Bu}$ nedenle bilgiyi ezberleyen bireyler yerine bilgiyi üreten, gerekli olan bilgiye ulaşabilen ve doğru bir şekilde kullanabilen bireylere ihtiyaç duyulmaktadır [2]. Diğer taraftan teknolojiyi eğitim sürecine katmak tek başına yeterli değildir. Öğretmenlerin teknoloji kullanımı hakkında yeterli bilgi ve beceriye sahip olması gerekir [3]. Teknoloji sayesinde eğitim ortamlarını etkin ve verimli kullanabilmek için öğretmenlerin teknolojiyi amacına uygun biçimde kullanma yeteneklerine sahip olması önemlidir [4]. $\mathrm{Bu}$ nedenle öğretmenlerin teknolojiyi yakından takip etmeleri ve teknolojinin olumlu yönlerini eğitim ortamında kullanabilmesi gerekmektedir.

Son yıllarda hızla gelişen donanım, yazılım ve ağ teknolojileri o kadar çok kullanım alanına sahip oldu ki eğitim hizmetlerinin bu alan dişında kalması düşünülememektedir [5]. Eğitim alanında kullanılabilecek olan teknolojilerin artması ile eğitimcilerin de bu teknolojileri tanıması ve kullanabilmesi konusunda 
önemli bir rolü üstlenmeleri gerekmektedir. Bu amaçla eğitimcilerin teknolojik gelişmeleri takip ederek alanlarına uygun teknolojileri kullanmaya önem göstermeleri gerekmektedir.

Sanal materyallerin kullanılması günümüz teknolojisi sayesinde önemli ölçüde değer kazanmaya başlamıştır. Sanal materyaller arasında video ve animasyonlar önemli bir yere sahiptir. Videolar sayesinde öğrenciler öğrenmeleri gereken bilgileri eğitim ortamlarına ihtiyaç duymadan tekrar yaparak bilgilerini taze ve kalıc tutabilirler. Diğer taraftan animasyonlar sayesinde ise öğrenciler içerik ile etkileşiminde bulunabilirler. Öğrenciler soyut kavramları somutlaştırabilecek ve ögrenmelerini daha etkili bir hale getirebileceklerdir. Eğitimin hedefleri doğrultusunda hazırlanan animasyon ve videolar ile destekli materyaller sayesinde öğrencilerin bilgilere karşı merak duygularının artması da sağlanmış olacaktır. $\mathrm{Bu}$ durumun sonucunda ise kavramların öğrenilmesi ve hatırlanması kolaylaşacaktır.

Bilgisayarlar öğretim faaliyetlerinde en fazla kullanılan teknolojik araçlardan olmuştur. Ancak bilgisayarların plansız kullanımı faydanın yanında zarar da getirebilmektedir. $\mathrm{Bu}$ yüzden amacina uygun planlanmalıdır [6]. Eğitimciler eğitim yazılımları kullanarak öğrencilerine zengin bir öğrenme ortamı sağlamış olurlar. $\mathrm{Bu}$ amacı gerçekleştirmeye yönelik güncel yazılımlardan biri de artırılmış gerçekliktir. AG öğrencileri geleneksel sınıf ortamından uzaklaştırıp, alışılagelmiş bilgisayar teknolojisinin aksine, gerçek objeler ile gerçek zamanlı etkileşim kurmalarını sağlar [7]. Artırılmış gerçeklik gerçek nesnelerin bilgisayar ortamında sanal nesneler ile birleşmesini sağlayan bir teknolojidir. Kamera ile gerçek nesnelerin üzerlerine resim, video veya metin gibi sanal nesnelerin yerleştirilmesini sağlar. Böylece kamera özelliğine sahip bilgisayar veya mobil cihazlar kullanılarak bakılan bir nesneye içerikler bütünleştirilerek görüntülenmektedir. AG'nin en önemli avantajı görselleştirme olanağ sunmasıdır. Bu sayede 3 boyutlu görselleştirmeler yolu ile ders içerikleri geliştirilebilmektedir. Ders içeriklerinin 3 boyutlu görsellerden oluşması öğrencilerin nesneleri zihinlerinde gerçekmiş gibi algılayarak döndürme ve çevirmesine imkân sağlamaktadır [8]. Bu özelliği sayesinde gerçek dünyada oluşturulması zor olan ortamların öğretimi uygun hale getirilmektedir [9].

Artırılmış gerçeklik üzerine yapılan çalışmalar son yıllarda birçok alanda AG'nin kullanıldığını göstermiştir. Mimarlık, Askeri Okullar ve Tıp alanlarının yanı sıra eğitim öğretimde Matematik, Geometri, Fizik, Kimya ve İngilizce gibi derslerde de artırılmış gerçeklik uygulamaları kullanılmıștır. Eğitim öğretimde kullanılan artırılmış gerçeklik uygulamaları genel olarak öğrencilerin öğrenme başarısı üzerine etkisini araştırmaya yöneliktir. Çetinkaya ve Akçay artırılmış gerçeklik uygulamalarının eğitimde kullanım alanlarını ve yapılan çalışmaları inceleyerek ortaya koymuştur [10]. Buna göre çalışmalar artırılmış gerçekliğin öğrenmeyi destekleyen bir unsur olduğunu göstermektedir. Artırılmış gerçeklik öğrencilerin derse yönelik tutum, motivasyon, ilgi, dikkat, güven ve memnuniyet gibi sağlıklı bir eğitim ortamını oluşturan değişkenleri etkilemesi açısından da önemli bulunmuştur.

Bu çalışmanın amacı; bilgisayar donanımı öğretiminde, bilgisayar donanımını oluşturan parçaların, laboratuvar ortamında uygulama yapılarak öğretilmesine alternatif bir yöntem oluşturmaktadır. Artırılmış gerçeklik teknolojisi kullanılarak geliştirilen öğretim materyali ile laboratuvar ortamına olan ihtiyacı azaltarak öğrencilerin kendi kendilerine uygulama yapıp öğrenebilecekleri bir alan oluşturulacaktır

\section{ARTIRILMIŞ GERÇEKLIK (AUGMENTED REALITY)}

Artırılmış gerçeklik, gerçek nesnelerin sanal nesneler ile eş zamanlı görüntülenmesini sağlayan bir teknolojidir [11]. Bir başka deyişle gerçek dünyanın sanal dünya ile bütünleşmesidir. Aynı zamanda bilgisayarda oluşturulan sanal nesnelerin teknolojik araçlar sayesinde insan bilincinde gerçek hissini veren ve bu his ile etkileşimde bulunmasını sağlayan bir teknolojidir [12]. AG, gerçekliğin baştan oluşturulması değil var olan bir gerçekliğin sanal ortamlar yoluyla desteklenmesidir [13]. AG, gerçek dünyanın bilgisayar sayesinde ses, görüntü, grafik ve GPS verileriyle birleşmesinden oluşan doğrudan veya dolaylı fiziksel görünümüdür. $\mathrm{Bu}$ sebeple gerçeklik algısı bilgisayar sayesinde artırılmıştır.

Günümüzde AG teknolojisinin eğlence, üretim, mühendislik, tıp ve eğitim gibi birçok alanda kullanımı yaygınlaşmıştır. Literatürde artırılmış gerçekliği açıklayan tanımlarda sanal nesneler ifadesi geçtiğinden dolayı artırılmış gerçekliğin sanal gerçeklik ile karıştırıldığı görülmektedir. Sanal gerçeklik gerçek olmayan ama insan bilincinde gerçeklik hissi veren bir sistemden meydana gelmektedir. Bir başka deyişle, gerçek dünya ortamının bilgisayarlar vasıtasıyla sanal ortamlarda oluşturulmasıdır [11]. Var olan gerçeklik yerine, gerçeklik hissi veren kurgusal bir sistemdir. Gerçek dünyaya bilgisayarlar tarafindan oluşturulan sanal eklentiler (ses, video, grafik) ile insanların gerçeklik hissini artırmayı yani zenginleştirmeyi amaçlayan bir sistemdir. Sanal gerçeklikte insan gerçeklikten soyutlanarak bilgisayar ile oluşturulmuş gerçek olmayan bir ortamdadır [14]. AG'de ise insan sanal nesneler ile birleştirilmiş gerçek bir ortamdadir. Milgram ve Kishino, AG'nin gerçek ve sanallık arasındaki yerini belirlemek amacıyla oluşturmuş olduğu basitleştirilmiş gerçeklik sanallık diyagramını Şekil 1' de gösterilmiştir [7].

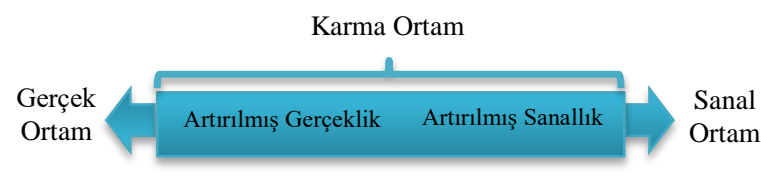

Şekil 1. Gerçeklikten sanallığa geçiş diyagramı (Simplified representation of a "virtuality continuum".) 
Şekil 1 incelendiğinde diyagramın soluna doğru gidildikçe gerçeklik artmaktadır. Bunula birlikte gerçek ortama eklenen sanal eklentiler sayesinde artırılmış gerçeklik meydana gelmektedir. Diyagramın sağına doğru gerçek ortamın hissini vermek amacıyla sanal nesnelerin oluşturduğu bir ortam oluşmaktadır. Sanal ortama gerçek nesnelerin eklenmesi ile de artırılmış sanallık meydana gelmektedir.

\subsection{Artırılmış Gerçeklik Teknolojisinin Eğitimde} Kullanılmasi (The Using Of Augmented Reality Technology In Education)

Artırılmış gerçeklik uygulamaları birçok alanda kullanılmasıyla son yıllarda eğitim alanında da kullanılmaya başlanmıștır [15]. Artırılmış gerçeklik teknolojisi öğrencilerin ufkunu açarak daha fazla duyu organlarını kullanmalarını sağlayıp ilgi ve merak gibi kavramları arttırmaya yardımcı olmaktadır [16]. AG teknolojisi ile eğitim öğretim ortamı birleștirildiğinde, kullanılan yeni teknoloji sayesinde öğrencilerin derse karşı ilgilerini çekerek öğrenme sürecinde aktif rol almaları ve aynı zamanda yaparak ve yaşayarak öğrenmeleri sağlanabilir [17].

Eğitimde artırılmış gerçeklik gerçek ortamda birden fazla duyu organına hitap edebilecek içerikler oluşturmak için sanal ortamın gerçek ortam ile bütünleştirilmesidir [18] Öğrencilerin öğrenme sürecinde eğlenmeleri ve öğrenme sürecine aktif olarak katılmaları etkili öğrenmeyi desteklemektedir. Artırılmış gerçeklik uygulamalarıyla öğrenci ile gerçeklik etkileşimi de artmaktadır [17] Öğrenciler öğrenmede aktif rol alabilmektedirler [19].

Artırılmış gerçekliğin eğitimde birçok faydası olduğu yapılan çalışmalarla gösterilmiştir. Bu faydaların bazıları şu şekilde sıralanabilir:

- Öğrencinin yaratıcılık ve hayal gücünün gelişmesine yardımcı olur. Gerçek dünyaya algısını ve gerçek dünya ile etkileşimini artırarak öğrenme üzerinde istekli hale getirir [20].

- Çeşitli öğrenme stillerine uygun özgün bir öğrenme ortamı yaratabilir [21].

- Sanal ve gerçek nesnelerin birleştirilmesi öğrencinin etkinliğe kendini vermesini sağlar [17].

- Öğrencilerin bakış açısına göre bilgiler güncellendiği için süreklilik sağlar [16].

- Gerçek zamanlı etkileşim sağladığından, öğrenci-içerik etkileşimine katkıda bulunur [17].

- AG kullanımı ile soyut olan kavramlar somutlaştırılarak öğrencilerin anlamaları kolaylaştırılır [22].

- Yeni bir teknoloji olması ilgi ve merak uyandirması sayesinde eğlenerek öğrenmeyi sağlar [17].

- Öğrenci motivasyonunu artırır [23].
- AG teknolojisi kullanılarak yapılan öğretim ilgi ve merak uyandırdığı için öğrenilmesi ve öğretilmesi zor olan konuların anlaşılmasında kolaylık sağlar[19][24].

- Gerçek dünyada oluşturulamayacak ortam ve etkileşimler AG sayesinde mümkün olmaktadır [16].

Yukarıda listelenen faydaları artırılmış gerçekliğin eğitimde farklı alanlarda ve eğitsel amaçlarla kullanılmasına ve araştırılmasına kapı aralamıştır. Örneğin, AG matematik ve geometri eğitiminde sıklıkla kullanılmıştır. Kaufmann ve Schmalstieg, Construct3D isimli çalışmasında Matematik ve Geometri için 3 boyutlu AG ortamı geliştirmişlerdir [21]. Yapılan uygulama öğrencilerin uzamsal gelişimini gözlemlemek amaciyla yapılmıştır [25]. İbili ve Şahin ise çalışmalarında geometrik cisimler ile AG uygulaması geliştirerek öğrenci başarısı ve derse karşı tutumu araştırmışlardır [19].

Billinghurst, Kato ve Poupyrev "Magic Book" isimli uygulama geliştirerek çocuklar için hikâye kitaplarını animasyonlarla zenginleştiren bir öğrenme ortamı geliştirmişlerdir. Kitapta bulunan resimler, artırılmış gerçekliğin entegre edildiği bir mobil cihaz ile bakıldığında üç boyutlu halde görülebilir olması sağlanmıștır. $\mathrm{Bu}$ sayede sanal karakterler AG ile desteklenmiştir [14].

Taşkıran, Koral ve Bozkurt artırılmış gerçekliğin yabancı dil öğrenimine entegre edilmesi sonucunda öğrencilerin AG hakkında görüşlerini değerlendirmişlerdir [17]. Di Serio, Ibáñez ve Kloos ise çalışmalarında ortaokul seviyesindeki öğrencilere uygulanan AG uygulamasının motivasyona, dikkate, ilgi ve memnuniyete etkisini incelemişlerdir [26].

Shelton ve Hedley ise yapmış oldukları çalışmada Coğrafya ile ilgili dönme, gündönümü, 1ş1k ve sıcaklığın mevsimsel değişimi gibi kavramların öğretimi için AG uygulamasını kullanmışlardır. AG ile öğrencilerin soyut kavramları daha iyi anladıkları ve kavram yanılgısını azalttıkları sonucuna ulaşmışlardır [9].

AG fizik eğitimi alanında da kullanılmıştır. Matcha ve Rambli fizik eğitiminde elektrik konusu ile ilgili hazırladıkları AG uygulamaları ile öğrencilere işbirlikçi bir öğrenme ortamı sunmuşlardır [27]. Abdüsselam ve Karal manyetizma konusunda AG materyallerinin öğrenci başarısı üzerine olumlu etkilerini gözlemlemişlerdir [22].

\subsection{Artırılmıș Gerçeklik Teknolojisinin Kullanılan Bileşenine Göre Türleri (Types Used By Components of The Augmented Reality Technology)}

AG teknolojisi, kullanım alanı olarak ikiye ayrılmaktadır, bunlar:

- Konum tabanlı AG uygulamaları

- Resim tabanlı AG uygulamalarıdır. 
Konum tabanlı AG uygulamaları, GPS sinyalleri ile konum tespit edilerek kullanıcının bulunduğu gerçek dünyaya sanal eklentiler eklenmesi esasına dayanır. Layar ve Wikitude isimli Android ve IOS platformunda desteği olan uygulamalar konum tabanlı AG' ye örnektir. Şekil 2' de GPS modülü yardımıyla gerçek ortamın koordinatlarında tanımlanan yerlere sanal eklentiler yapılması örneklenmektedir.

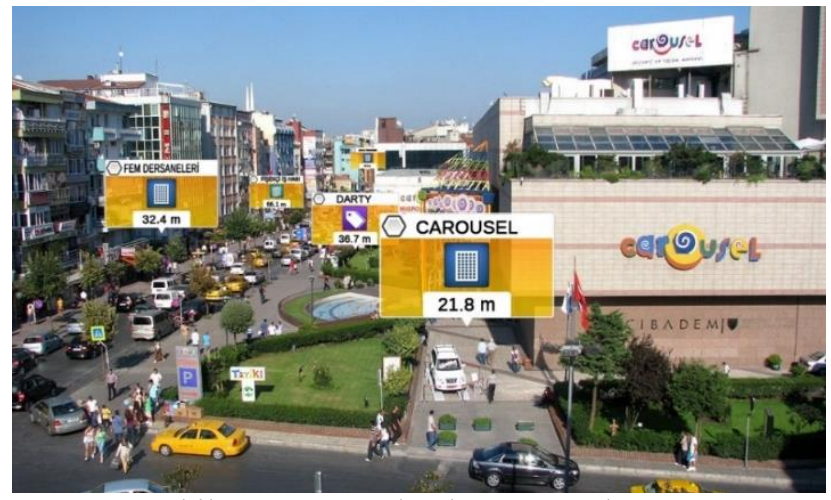

Şekil 2. Konum tabanlı AG uygulaması (Location Based AR Application)

Resim tabanlı AG uygulamaları ise gerçek dünya üzerine ses, görüntü ve video eklentileri yaparak oluşturulan uygulamalardır. Bu uygulama türü de kendi içerisinde iki gruba ayrilır, bunlar:

- İşaretçi tabanlı uygulamalar

- İşaretçi tabanlı olmayan uygulamalar

İşaretçi tabanlı AG uygulamalarında gerçek ortamdaki nesneleri tanıtmak için önceden sisteme tanıtılmış işaretçilerin olması gerekir. Gerçek ortam ile sanal eklentileri birleştirmek için işaretçiler referans alınır. İşaretçi olmayan AG uygulamalarında gerçek ortama işaretçi eklemek yerine gerçek ortamdaki nesneler kullanılmaktadır. Şekil 3'de resim tabanlı AG uygulamasına örnek verilmiştir.

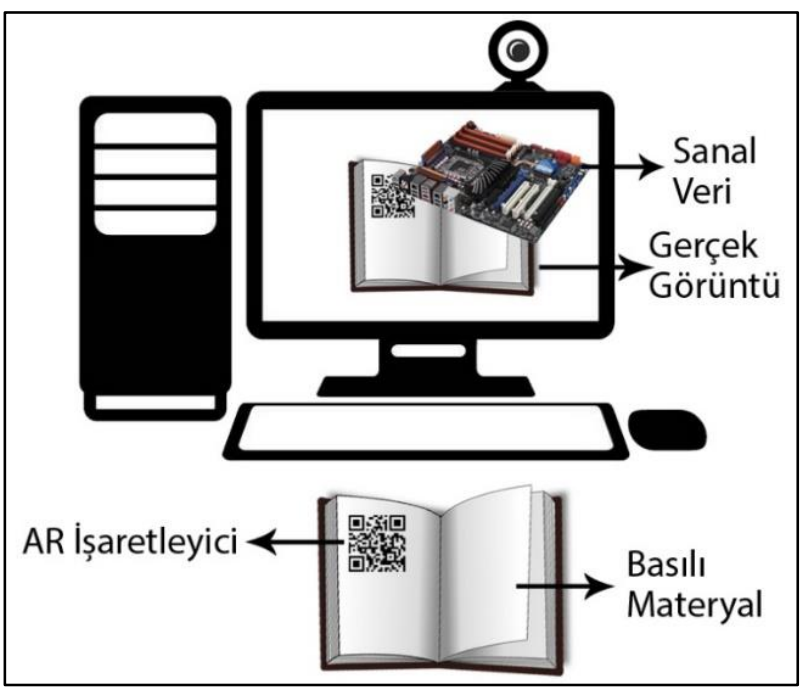

Şekil 3. Resim tabanlı AG uygulaması (Image Based AR Application)

\section{YÖNTEM (METHOD)}

\subsection{Araştırmanın Modeli (Research Model)}

Araştırma yarı deneysel yöntem kullanılarak yürütülmüştür. Yarı deneysel yöntem örneklemin rastgele seçilemediği ve deneysel gruplara rastgele atanamadığ durumlarda kullanılan bir deneysel yöntemdir.

\section{2. Örneklem (Sample)}

Örneklem, meslek yüksekokulu bilgisayar programcıllı̆̆ bölümünde öğrenim gören 122 öğrenciden oluşmaktadır. A şubesinde öğrenim gören öğrenciler deney grubuna, B şubesinde öğrenim gören öğrenciler kontrol grubuna atanmıştır. Deney grubu öğrencilerine bir eğitim öğretim dönemi boyunca AG öğrenme materyali kullandırılmıştır. Kontrol grubu öğrencilerine ise AG öğrenme materyali kullandırılmadan eğitime devam edilmiştir.

\subsection{Veri Toplama Araçları (Data Collection Tools)}

Araştırmada veri toplamak için başarı testi ve öğrenci görüşlerini almak için bir görüş anketi ve görüşme formu kullanılmıştır. Tablo 1' de araştırma soruları ile birlikte kullanılan veri toplama araçları gösterilmektedir.

Tablo 1. Veri toplama araçları (Data collection tools)

\begin{tabular}{ll}
\hline Araştırma Soruları & Veri Toplama Aracı \\
\hline $\begin{array}{l}\text { Deney ve kontrol gruplarının uygulama } \\
\text { öncesi ve uygulama sonrası başarı düzeyleri }\end{array}$ & Başarı Testi \\
arasında anlamlı bir fark var mıdır? & \\
\hline $\begin{array}{l}\text { Deney grubunu oluşturan öğrencilerin } \\
\text { uygulama hakkında memnuniyetliklerine }\end{array}$ & AG Görüş Anketi \\
$\begin{array}{l}\text { ilişkin görüşleri nelerdir? } \\
\text { Öğrencilerin artırılmış gerçeklik öğrenme }\end{array}$ & \\
$\begin{array}{l}\text { materyali uygulamasına yönelik görüşleri } \\
\text { nelerdir? }\end{array}$ & AG Görüş Formu \\
\hline
\end{tabular}

\subsubsection{Başarl Testi (Achievement test)}

Ders içerikleri dikkate alınarak, öğrenim kazanımları doğrultusunda öğrencilerin ders başarılarını ölçmek amacıyla bir başarı testi geliştirilmiştir. Başarı testi için 100 soruluk bir soru havuzu oluşturulmuştur. Test geliştirilmesinde bilgisayar donanım dersi için hazırlanan ders içerikleri dikkate alınarak her bir kazanıma yönelik 40 sorudan oluşan çoktan seçmeli bir test hazırlanmıştır. Başarı testini uygulamadan önce, soruların öğrenciler tarafından kolayca anlaşılabildiğinin belirlenebilmesi ve gerekli düzeltmelerin yapılabilmesi için dersi daha önceden almış 60 öğrenci üzerinde pilot test yapılarak gerekli görülen düzeltmeler yapılmıştır. Test süresi 40 dakika olarak belirlenmiştir. Pilot uygulamadan elde edilen veriler üzerine madde analizleri de yapılarak teste son hali verilmiştir. Madde ayırt edicilik değeri ve madde güçlük değeri 0,20'nin altında olan 10 madde $(2,8,911$, $15,22,30,35,36,37)$ testten çıkarılmıştır. 30 sorudan oluşan başarı testinin ortalama madde güçlük değeri 0,48 , ayırt edicilik değeri 0.40 , KR-20 güvenirlik katsayısı ise 0,75 olarak bulunmuştur. Hesaplanan bu değere göre 
testin geçerlilik ve güvenirliliğinin yeterli olduğu sonucuna gidilmiştir [28].

\subsubsection{Görüş Anketi (AG Opinion scale)}

Deney grubu öğrencilerinin bilgisayar donanım dersinde yapılan uygulamaya yönelik görüşlerini ortaya çıkarmak amacıyla bir görüş anketi hazırlanmıştır. Anket için teknoloji kabul modeli temel alınmış ve bu modele göre hazırlanmış ve Küçük'ün araştırmasında Türkçe uyarlaması yapılmış olan bir anket temel alınarak hazırlanmıştır [29]. TKM temel olarak bireylerin yeni bir teknolojiyi kabulü üzerine odaklanmaktadır. Davis ve Davis, Bagozzi ve Warshaw teknoloji kabul modelini, bireylerin kullandıkları yeni teknolojiyi kabul etmelerinde neyin etkili olduğunu tespit etmeye yönelik bir modelleme olarak açıklamışlardır [30][31]. Fishbein ve Ajzen tarafından geliştirilen TK bireylerin davranışlarını açıklamak amacıyla kullanılan sebepli davranış kuramının bir uygulaması olarak görülmektedir [32]. Bu çalışmada TKM, yeni bir teknoloji olan AG uygulamasının öğrencilere kabulünü ölçmek üzere kullanılmıştır. Anket 5'li likert türünde olup 23 maddeden oluşmaktadır. Anket soruları 7 faktör olarak gruplandırılmıştır. Anketin Cronbach alfa güvenirlik katsayısı 0,83’tür.

\subsubsection{Artırılmış Gerçeklik Görüşme Formu (Augmented reality interview)}

Deney grubu öğrencilerinin AG'nin etkililiğine yönelik görüşlerini almak için 9 sorudan oluşan yarı yapılandırılmış görüşme formu hazırlanmıştır. Görüşme deney grubundan 10 öğrenci ile gerçekleştirilmiştir.

\subsection{AG Öğrenme Materyali (AG learning material)}

Çalışma kapsamında bilgisayar donanım öğretimi için AG öğrenme materyali hazırlanmıștır. Olușturulan öğrenme materyali ile her öğrenci mobil platformda bilgisayar parçalarını görebilecekleri, uygulama yapabilecekleri aynı zamanda resim, video ve ses ile desteklenen interaktif bir öğrenme ortamını kullanmaları sağlanmıştır. AG öğrenme materyali araştırmacı tarafından geliştirilmiştir. Hazırlanan materyal öğrencilerin bilgisayar donanım dersi için ders notu şeklinde olup kullanılan resimler ve kare kodlar ile telefonlarını kullanarak ilgili görsel hakkında bilgi alıp uygulama yapabilecekleri bir ortam sunulmuştur.

AG öğrenme materyali geliştirme aşamasında ilk olarak pilot çalışmada masaüstü bilgisayarlar kullanılmıştır. AG öğrenme materyali için Visual Studio, Unity, ve Android Studio programları kullanılarak C\# ve Java dilleriyle uygulama geliştirilmiştir. AG temelinde gerçekliği zenginleştirmek anlamına geldiği için gerçek ortamlara eklenen üç boyutlu sanal eklentiler 3D Studio Max, Maya, Adobe Paket Programları gibi grafik tabanlı yazılımlar ile hazırlanmıştır.
Sanal nesnelerin gerçek ortamlarda görüntülenmesi için işaretçilere (marker) ihtiyaç duyulmuştur. AG öğrenme materyalinde kare kodlar, gerçek objeden oluşan görüntüler ve metin tanıma gibi işaretçiler kullanılmıştır. İşaretçileri tanımlama aşamasında $\mathrm{AG}$ yazılım geliştirme kitleri kullanılmıştır. Vuforia, Wikitude ve Qualcomm gibi çevrimiçi veya bilgisayara yüklenebilen yazılım geliştirme kitleri sayesinde işaretçiler tanımlanmıştır.

AG öğrenme materyali hazırlanırken alan yazında bahsedilen birçok program ve yazılım geliştirme kiti denenmiştir. Denemeler sonucunda en kararlı çalışan sistem ile uygulama yapılmıştır. Uygulama geliştirme aşamasında Unity 3D isimli oyun geliştirme programı kullanılmıştır. Yazılımların kararlı bir şekilde çalışabilmesi için Windows işletim sistemi $32 \mathrm{Bit}$ versiyonu tercih edilmiştir. İşaretçiler için Vuforia yazılım geliştirme kiti Unity 3D programıla birlikte çalışacak şekilde entegre edilmiştir. Gerçek ortamları zenginleştirmek için sanal 3 boyutlu nesneler 3D Studio Max programı ile .3ds dosya uzantısı olacak şekilde hazırlanıp, Unity 3D programına dahil edilerek uygulama hazırlanmıştır.

Pilot çalışma için masaüstü bilgisayarda çalışacak şekilde exe ve html dosya uzantılı program çıktısı alınmıştır. Bilgisayar sınıfında öğrencilerin kullandığı bilgisayarlara dosyalar kopyalanarak pilot çalışma için uygulama ortamı hazırlanmıştır. Şekil 4'de pilot çalışma için yapılan uygulamaya örnek ekran görüntüsü verilmiştir.
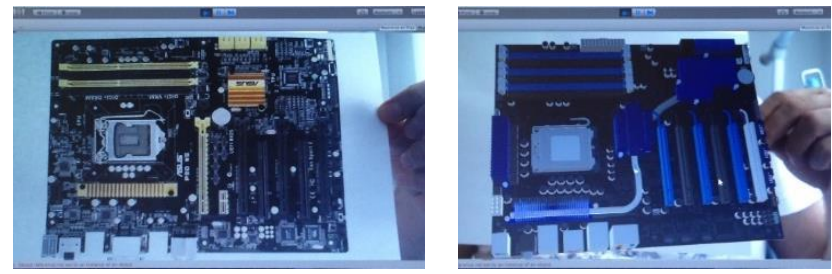

Şekil 4. Pilot çalışma uygulama görüntüsü (Pilot Application Image)

Uygulamanın pilot aşamasında aşağıdaki sınırlılıklar gözlenmiştir.

- Öğrencilerden bazıları AG teknolojisini ilk kez gördükleri için uygulamayı kullanmada zorlanmışlardır.

- Masaüstü bilgisayarlara takılan kameraların yeterli düzeyde olmamasından dolayı kullanımda aksaklıklar meydana gelmiştir.

- 3 boyutlu sanal eklentiler ile gerçek ortamın yeterli düzeyde uyumlu olmadığı tespit edilmiştir.

Pilot uygulamada karşılaşılan aksaklıklar düzeltilerek asıl uygulama mobil platform üzerinde Android işletim sisteminde çalışacak şekilde hazırlanmıştır.

AG öğrenme materyali Bilgisayar Programcılığg 1. sınıf öğrencilerine kullandırılmıştır. İlk 2 hafta öğrencilere 
pilot uygulama kullandırılıp öğrencilerin AG teknolojisi hakkında bilgi almaları ve asıl yapılacak olan uygulama için çözümler üretilmiştir. Takip eden sürenin devamında 1 hafta boyunca başarı testi (ön-test) yapılmıştır. Geri kalan 7 hafta boyunca AG ögrenme materyali uygulaması çalışılmıştır. $\mathrm{Bu}$ sürenin içerisinde 1 hafta eğitime ara verilmesinden dolayı toplamda 6 hafta $\mathrm{AG}$ öğrenme materyali ile dersler anlatılmıştır.

Mobil destekli AG uygulaması için pilot çalışmada kullanılan Vuforia yazılım geliştirme kiti tercih edilmiştir. Unity 3D programı için kullanılan yazılım geliştirme kitinin programa uygun olan eklentisi bilgisayara kurulmuştur. Şekil 5' da Unity 3D programı için Vuforia yazılım geliştirme kitinin bilgisayara indirilmesi gereken eklentinin ekran görüntüsü verilmiștir.

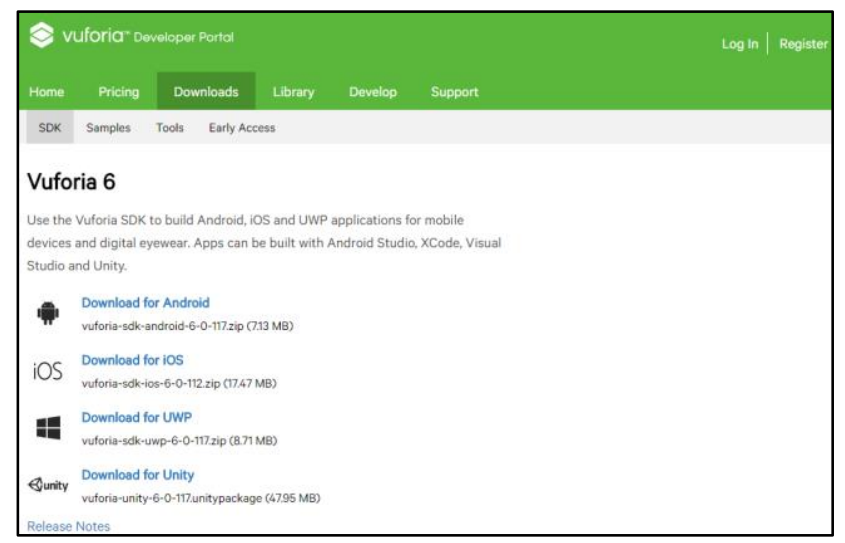

Şekil 5. Vuforia 6 SDK eklentisi (Vufori 6 SDK plugin)

Şekil 5 incelendiğinde Vuforia sisteminde hesap açıldıktan sonra "Develop" sekmesi kullanılarak işaretçiler sisteme yüklenir. Yüklenen işaretçiler ile oluşturulan lisans anahtarı Unity 3D programına yüklenerek işaretçilere program içerisinden erişme imkânı sağlanmış olur. İşaretçiler gerçek görüntülerin resim formatlarında (.jpg) yüklenmiştir. Aynı zamanda karekod veya metin işaretçileri için aynı yöntem kullanılarak resim formatlarında sisteme dahil edilmiştir.

3 boyutlu sanal eklentiler 3D Studio Max programında hazırlanmıştır. 3 boyutlu sanal eklentiler, $3 \mathrm{ds}$ veya obj formatlarında oluşturulmuştur. Unity 3D programında işaretçiler ve sanal eklentiler ile birlikte öğretim materyali hazırlanmıştır. Şekil 6'da Unity programının tasarım ekranından bir örnek verilmiştir.

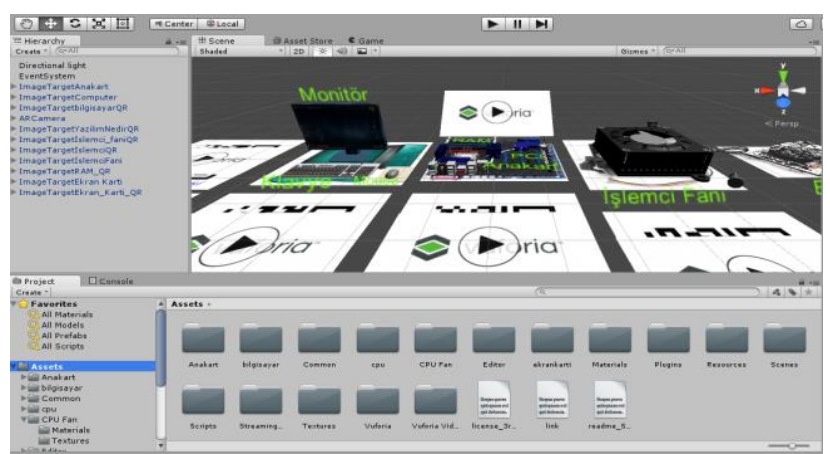

Şekil 6. Unity tasarım ekranı (Unity Design Screen)

Şekil 6'da Unity 3D programının tasarım ekranı gösterilmektedir. Uygulama hazırlandıktan sonra farklı platformlarda uygulamanın çalışabilmesi için dosyalar üretilmiştir. Unity 3D programında hazırlanan $\mathrm{AG}$ öğrenme materyali masaüstü bilgisayarda, web ortamında, IOS ve Android işletim sistemine sahip cihazlarda çalışması sağlanmıştır. Deney grubu öğrencilerinin mobil cihazlarında Android işletim sistemi kullanımının fazla olması ve kolay erişimin sağlanmasından dolayı Android cihazlarda çalışabilecek program çıktısı üretilmiştir.

Şekil 7'de hazırlanan AG öğrenme materyalinden bir sayfa görüntüsü verilmiştir.

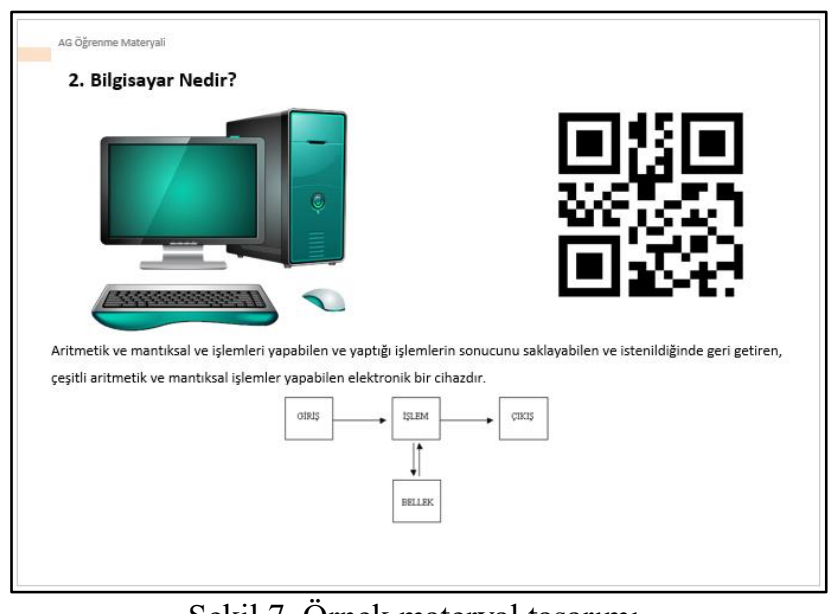

Şekil 7. Örnek materyal tasarımı (Sample Material Design)

Şekil 7'de verilen örnek materyal görüntüsünde, öğrencilerin cihazlarına yüklenen uygulama kullanılarak hazırlanan yazılı materyalin üzerine getirilip 3 boyutlu görseller ve animasyonlar cihazların ekranlarında görüntülenmektedir. Bu sayede öğrenciler sadece yazılı materyale bağlı kalmaksızın gerçek görüntüler ve animasyonlar ile daha fazla uygulama yapma imkânları bulmuş olurlar.

\section{BULGULAR (RESULTS)}

4.1. "Deney ve kontrol gruplarının uygulama öncesi ve uygulama sonrası başarı düzeyleri arasında anlamlı bir fark var mıdır?" Araştırma Sorusuna Ait Bulgular ("Is there a significant difference achievement levels between experimental 
and control groups prior of application and later of application?" results of research question)

Deney grubu öğrencilerinin öntest ve sontest puanları arasında anlamlı bir farklılık olup olmadığına ait bulgular Tablo 2' de verilmiștir. Öntest puanlarının ortalamaları ve standart sapma değerleri de Tablo 3 'te verilmiştir.

Tablo 2. Deney grubu öğrencilerinin öntest ve sontest başarı puanlarının karşılaştırılmasına ilişkin sonuçları

(The results of comparsion for students achievement pre-test and post-

\begin{tabular}{|l|l|c|c|c|c|c|c|}
\hline \multirow{2}{*}{ Grup } & Testler & $\boldsymbol{N}$ & $\overline{\mathrm{X}}$ & $\boldsymbol{S S}$ & $\boldsymbol{t}$ & $\boldsymbol{S d}$ & $\boldsymbol{p}$ \\
\hline \multirow{2}{*}{ Deney } & Öntest & 61 & 20,58 & 2,81 & \multirow{2}{*}{ test } & 59 & \multirow{2}{*}{.000} \\
& Sontest & 61 & 22,53 & 3,77 & & & \\
\hline
\end{tabular}

Tablo 2 incelendiğinde deney grubu öğrencilerinin AG öğrenme materyalini kullanmadan önceki başarı testi ortalama puanı $\overline{\mathrm{X}}=20,58^{\prime}$ dir. AG öğrenme materyalini kullandıktan sonra başarı testi ortalama puanı $\overline{\mathrm{X}}=22,53$ olduğu görülmektedir. Ortalama başarı puanındaki bu artış; puanlar arasında anlamlı bir fark olduğunu göstermektedir $(\mathrm{t}(59)=-4,286 ; \mathrm{p}<, 05)$. Analiz sonucunda erişilen bulgu, AG öğrenme materyalinin öğrencilerin başarılarında olumlu yönde bir durum oluşturduğu anlamında yorumlanabilir. Ortalamalar arasındaki farkın etki büyüklüğüne bakıldığında 0,58 değeri bulunmuştur. $\mathrm{Bu}$ sonuç deney grubu öğrencilerinin öntest ve sontestleri arasında orta büyüklükte bir etki olduğunu göstermektedir.

Tablo 3. Deney ve kontrol grubu öğrencilerinin öntest başarı puanlarının aritmetik ortalama, standart sapma ve standart hata değerleri

(Arithmetic mean, standart deviation and standart error values of pretest succes points of experimental and control group students)

\begin{tabular}{|l|l|c|c|c|c|c|c|}
\hline Grup & Testler & $\boldsymbol{N}$ & $\overline{\mathrm{X}}$ & $\boldsymbol{S S}$ & $\boldsymbol{t}$ & $\boldsymbol{S d}$ & $\boldsymbol{p}$ \\
\hline Deney & \multirow{2}{*}{ Ontest } & 61 & 20,58 & 2,812 & \multirow{2}{*}{0,181} & 117 &, 857 \\
Kontrol & & 61 & 20,42 & 3,766 & & & \\
\hline
\end{tabular}

Tablo 3 incelendiğinde AG öğrenme materyalini kullanan deney grubu öğrencilerinin öntest başarı puan ortalaması $\overline{\mathrm{X}}=20,58$ olarak hesaplanmıştır. Kontrol grubu öğrencilerinin ön test başarı puan ortalaması $\bar{X}=20,42$ olarak hesaplanmıştır. Deney ve kontrol gruplarının öntest başarı puanları karşılaştırılması için yapılan ilişkisiz örneklemler t-testi sonrasında grupların deneysel işlem öncesinde denk oldukları bulunmuştur $(\mathrm{p}>0,05)$.

4.2. "Deney grubunu oluşturan öğrencilerin uygulama hakkında memnuniyetliklerine ilişkin görüşleri nelerdir?" araştırma sorusuna ait bulgular (What are the views of their pleasantness about application of the students in the experimental group? Results of the research question)

Deney grubu öğrencilerinin Bilgisayar Donanım dersi için geliştirilen AG öğrenme materyaline yönelik görüşlerini belirlemek amacıyla AG görüş anketi kullanılmıştır. AG görüş anketi 7 faktörden oluşmuş olup, her bir faktöre ilişkin ortalama ve standart sapma değerleri Tablo 4' de verilmiştir.

Tablo 4. Anketi oluşturan alt faktörlerin ortalamaları (The average value of the sub-factors that make the AG Opinion Survey)

\begin{tabular}{|l|c|c|}
\hline Alt Faktörler & $\bar{x}$ & SS \\
\hline Algilanan Memnuniyet & 4,14 & 0,78 \\
\hline Algilanan Fayda & 3,95 & 0,77 \\
\hline Etkililik & 4,05 & 0,76 \\
\hline Çoklu Ortam Öğretimi & 4,09 & 0,82 \\
\hline Sistem Kalitesi & 4,07 & 0,78 \\
\hline Algılanan Özyeterlik & 4,21 & 0,70 \\
\hline Niyet & 4,09 & 0,73 \\
\hline
\end{tabular}

Tablo 4 incelendiğinde deney grubu öğrencilerinin AG öğrenme materyali ile ilgili ortalama değer $\overline{\mathrm{X}}=4,08$ olarak bulunmuş olup ankette yer alan soruları olumlu yönde cevapladıkları söylenebilir.

\section{3. "Öğrencilerin artırılmış gerçeklik ögrrenme materyali} uygulamasına yönelik görüşleri nelerdir?" araştırma sorusuna ait bulgular (What are the opnions of the students about augmented reality learning material application? Results of research question)

AG öğrenme materyalini kullanan deney grubu öğrencileri ile ders dönemi sonunda görüşmeler yapılmıştır. Görüşmelerden elde edilen veriler araştırma soruları kapsamında betimsel analiz yöntemi ile analiz edilmiştir. Öğrenciler ile yapılan görüşmelerde AG öğrenme materyali hakkındaki düşüncelerini görüşme formunda yer alan sorular kapsamında cevaplandırmışlardır.

Pilot çalışma sonrasında yapılan görüşmelerde öğrenciler AG ile ilk kez karşılaştıklarından ve teknolojik imkânların kısıtlı olmasından dolayı kullanım zorlukları yaşadıklarını dile getirmişlerdir. Ayrıca kendi bilgisayarlarında uygulamayı çalıştırma konusunda sıkıntılar yaşadıklarını ifade etmişlerdir. $\mathrm{Bu}$ aksaklıklar uygulamanın mobil platformda çalışacak şekilde yapılması ile giderilmiştir.

Öğrencilerin bir kısmı bilgisayar donanım konusunda yeteri kadar bilgiye sahip olduklarını dile getirmişlerdir. Bir grup öğrenci uygulamadan önce derste sıkılacaklarını düşündüklerini ve bu nedenle derse karşı isteksiz olduklarını söylemişlerdir. Ancak uygulama sonrasında öğrenci görüşleri olumlu yönde değişiklik göstermiştir. AG teknolojisinin eğitimde kullanılmasının motivasyon, hayal gücü, derse karşı olan ilgi ve tutumu olumlu yönde etkilediği alan yazında bahsedilen özellikler arasında yer almaktadır. Benzer şekilde çalışma sürecinde öğrencilerin daha istekli oldukları da bulgular arasında yer almaktadır.

Öğrenciler AG teknolojisinin sadece eğitim amaçlı değil gerçek dünyada da kullanılması gerektiğini dile getirmişlerdir. Bir grup öğrenci ise diğer derslerinde de AG teknolojisinin kullanılmasının kendileri için faydalı olabileceği şeklinde düşüncelerini belirtmişlerdir. 
4.4. "Eğitmenlerin artırılmış gerçeklik öğrenme materyali uygulamasına yönelik görüşleri nelerdir?" araştırma sorusuna ait bulgular (What are the views of the lecturer about augmented reality learnin material? Results of the research question)

Çalışmanın hazırlanmasında, veri toplama kısmında ve uygulamanın gelişimi aşamasında eğitmenlerin görüşleri alınarak araştırma boyunca aktif rol almaları sağlanmıştır. Farklı birimlerdeki bilgisayar programcılığı bölümünde görevli olan öğretim elemanlarının derslerinde kullanmaları için araştırma da geliştirilen AG öğrenme materyali önerilmiştir. Materyali kendi derslerinde kullanan öğretim elemanları ile görüşmeler yapılarak düşünceleri alınmıştır.

Öğretim elemanları AG öğrenme materyalini kullanan öğrencilerin derse karşı motivasyonlarının arttığını gözlemlemişler ve öğrencilerin derse karşı daha istekli olduklarını ifade etmişlerdir.

Öğrencilerin AG öğrenme materyalini kullanmaları dersin öğrenci merkezli olmasını sağlamıştır. $\mathrm{Bu}$ sayede öğrenciler içerik ile etkileşimde bulunmuşlardır. Bunun sonucu olarak eğitmenler eğitimde yönlendirici rolünü üstlenmiş olup öğrenciler ise eğitimde aktif rol almışlardır.

\section{SONUÇ (CONCLUSION)}

AG öğrenme materyali ile desteklenen öğretimde öğrencilerin daha başarılı oldukları sonucuna ulaşılmıştır. Benzeri araştırmalarda da AG teknolojisi ile desteklenen eğitim öğretim ortamlarında kullanılan materyallerin öğrencilerin başarılarını arttırdığı sonucu elde edilmiştir [12][18]. Nitel ve nicel veriler birlikte incelendiğinde AG öğrenme materyalinin öğrenciler üzerinde olumlu bir etki bıraktığı aynı zaman da ders memnuniyeti arttırdığı olduğu görülmüştür. Bunun sonucu olarak AG'nin eğitim kalitesini olumlu yönde etkilediği sonucuna ulaşılmıştır.

Kaliteli bir eğitim ve öğretim ortamında dikkat edilmesi gereken önemli konulardan biri öğrencilerin derse olan ilgisi ve isteğidir. AG öğrenme materyalinin animasyonlar ve videolar içermesi, bunlara ek olarak mobil teknolojinin kullanılması öğrencilerin sürekli olarak derse olan ilgi ve dikkatlerini toplamada önemli olmuștur. Alan yazında AG uygulamalarının öğrencilerin ilgi ve dikkatlerini derse çektiği [19] ve motivasyonlarını artırdığı [17] belirtilmektedir. Bununla birlikte AG uygulamalarının öğrencilerin derslerine bakış açılarının da olumlu yönde etkilediği vurgulanmaktadır [34].

AG öğrenme materyalinin eğitimde kullanılması, öğrencilerin birbirleri arasındaki etkileşimi artırdığ sonucuna da ulaşılmıştır. AG teknolojisi gerçek ortamdan soyutlanmadan sanal nesneler ile gerçeği zenginleştirmeye olanak sağlar [17]. Aynı zamanda sosyal ilişkileri kuvvetlendirerek işbirlikçi öğrenmeye olanak sağlamaktadır [14]. Bu bakımdan $\mathrm{AG}$, gerçek dünyadan uzaklaştıran sanal ortamlar için alternatif bir yöntem oluşturmaktadır. Öğrencileri sınıf ortamından uzaklaştırmadan doğal bir etkileşim kurmasının etkili olduğu düşünülmektedir.

AG öğrenme materyalini kullanan öğrenciler ile yapılan görüşmeler sonucunda genel olarak derse karşı olan ilgi ve motivasyonlarının arttığına yönelik olumlu sonuçlar elde edilmiştir [19]. Bu sonuçların olumlu yönde olmasının en önemli sebeplerinden biri; Bilgisayar Programcılığı bölümünde okuyan öğrencilerin teknolojiye karşı ilgilerinden kaynaklı olmasıdır. AG'nin yeni bir teknoloji olması ve uygulama alanının oldukça geniş olması öğrencilerin derse karşı ilgilerini olumlu yönde etkilemiştir. Bu durum sayesinde öğrencilerin materyali kullanma istekleri uygulama boyunca devam etmiştir. Derse karşı olan ilgilerinden artmasından dolayı başarı testleri sonucunda elde edilen veriler öğrencilerin olumlu yönde ilgilerini destekler nitelikte olduğunu göstermektedir.

Öğrencilerin AG teknolojisini rahatlıkla kullanabildikleri ve ilk defa bu teknolojiyle karşılaşan kullanıcıların dahi kolaylıkla kullanabileceği sonucuna ulaşılmıştır. Öğrenciler ile yapılan görüşmelerde AG öğrenme materyalini kullanımı için herhangi bir eğitime gerek olmaksızın kullanımının oldukça kolay olduğuna dikkat çekmişlerdir. Alan yazında AG uygulamalarının öğrenciler tarafından kolaylıkla kullanılabilir olduğunu gösteren çalışmalar mevcuttur [20][24]. Bu sonuç, pilot uygulamanın eksikleri tespit edilerek çözüme kavuşturulması ve alan uzmanlarının görüşleri alınarak AG öğrenme materyalini öğrencilerin becerilerine göre hazırlanmasında etkili olduğu düşünülmektedir.

Pilot çalışma masaüstü bilgisayarlarda çalışabilecek şekilde tasarlanmıştır. Alan yazında da ayrıntılı olarak bahsedildiği üzere işletim sistemi, yazılımların uyumluluğu, kamera kalitesi gibi etkenlerden dolayı pilot çalışmada aksaklıklar meydana gelmiştir. Asıl uygulama dikkate alınarak pilot çalışmada gerekli düzeltmeler yapılmıştır. Öğrencilerin bilişsel düzeyi düşünüldüğünde uygulamanın mobil teknoloji destekli olmasına karar verilmiştir. Öğrencilerin kendi telefon veya tabletlerinde kullanılabilecekleri uygulama geliştirilmiştir. $\mathrm{Bu}$ durum başka derslerde de öğrencilerin AG öğrenme materyalini kullanma isteklerini desteklemiştir. Aynı zamanda AG öğrenme materyalini kullanımından memnun kaldıkları sonucuna ulaşılmıştır.

Öğrenciler AG öğrenme materyalinin eğitimde kullanılmasının dersleri ilginç ve keyifli hale getirdiğini ifade etmişlerdir. Eğitim öğretimde alışılagelmiş öğretim materyali kullanımı öğrencilerin ilgi, dikkat ve isteklerini yeteri kadar karşılayamamaktadır [25]. AG öğrenme materyalinin öğrenci içerik etkileşimine imkân tanıması, gerçeğe yakın üç boyutlu resimler ve videolar ile zenginleştirilmesi, derslere karşı ilginin ve dikkatin artırmasında önemli rol oynamaktadır. AG teknolojisinin öğrenmeyi keyifli hale getirdiğini gösteren çalışmalarda [19][24] bu sonucu destekler niteliktedir. Öğrencilerin AG öğrenme materyalinin kullanıldığı benzer dersler 
almak istemişlerdir. Alan yazında öğrencilerin AG teknolojisini tekrar kullanmak istedikleri sonucu desteklenmektedir [29][34]. Bu sonuç AG öğrenme materyalini kullanan öğrencilerin uygulamadan memnun kaldıklarını göstermektedir.

Sonuç olarak AG destekli bilgisayar donanım öğretiminin laboratuvar ortamına bağlı kalmadan sınıf ortamında da kullanılabileceği görülmüştür. Öğrenciler ile yapılan görüşmelerde birçok ders için AG öğrenme materyalinin kullanılabileceğini ifade eden düşünceleri bu durumu destekler niteliktedir. AG destekli öğretim ortamlarının hazırlanma aşamasında güncel bilgiler ve yazılımlar takip edilerek uygulamanın yapılacağı hedef kitlenin bilgi ve yeteneklerine uygun olması önerilmektedir. Çalışmaların geniş bir süre ve konu dâhilinde hazırlanması AG'nin öğrenciler üzerindeki olumlu etkisini artırabilmektedir. Çalışma kapsamında AG öğrenme materyalini kullanan öğrencilerin başarıları olumlu yönde etkilenmiştir. Öğrenci görüşleri bu başarıyı destekler niteliktedir. İleride yapılacak olan çalışmalarda; tutum, cinsiyet, grupla öğrenme vb. değişkenlerin sonuçlar üzerindeki etkilerinin araştırılması önerilmektedir.

\section{KAYNAKLAR (REFERENCES)}

[1] A. İşman and S. Gürgün, "Özel Okullarda Öğrenim Gören Ilköğretim Öğrencilerinin Internete Yönelik Tutum Ve Düşünceleri (Acarkent Doğa Koleji Örneği)," The 8th International EducationaI Technology Conference, 2008.

[2] B. Caymaz, Fen ve teknoloji ve sınıf öğretmeni adaylarının fen ve teknoloji okuryazarlığına ilişkin öz yeterlik algıları, Yüksek Lisans Tezi, Hacettepe Üniversitesi, Sosyal Bilimler Enstitüsü, 2008 .

[3] M. J. Koehler and P. Mjshra, "What happens when teachers design educational technology? The development of technological pedagogical content knowledge," Journal of Educational Computing Research, 32(2), 131-152, 2005.

[4] H. Çelik and M. Kahyaoğlu, “Ilköğretim Öğretmen AdaylarınınTeknolojiye Yönelik Tutumlarının Kümeleme Analizi," Türk Eğitim Bilimleri Dergisi, 2007.

[5] M. Bulun, B. Gülnar, and S. Güran, "Eğitimde Mobi Teknolojiler," The Turkish Online Journal of Educational Technology, 3(2), 165-169, 2004.

[6] L. Barut, Fen Ve Teknoloji Öğretmenlerinin Eğitimde Teknoloji Kullanımına Yönelik Tutumları İle Bilgisayar Öz Yeterlik Algıları Arasındaki İlişki, Yüksek Lisans Tezi, Kahramanmaraş Sütçü İmam Üniversitesi, Fen Bilimleri Enstitüsü, 2015

[7] P. Milgram and F. Kishino, "A taxonomy of mixed reality visual displays," IEICE TRANSACTIONS on Information and Systems, 77(12), 1321-1329, 1994.

[8] B. Shelton and R. Stevens, "Using coordination classes to interpret conceptual change in astronomical thinking," Proceedings of the 6th international conference for the learning sciences, 634, 2004.

[9] B. E. Shelton and N. R. Hedley, "Using augmented reality for teaching Earth-Sun relationships to undergraduate geography students," ART 2002 - 1st IEEE International Augmented Reality Toolkit Workshop, Proceedings, 2002.

[10] H. Çetinkaya and M. Akçay, "Eğitim ortamlarında arttırılmış gerçeklik uygulamaları," Akademik Bilişim Kongresi, Antalya, 2013.
R. Azuma, "A survey of augmented reality," Presence:
Teleoperators and Virtual Environments, 6(4), 355-385, 1997.

[12] B. T. Çavaş, Bülent; Çavaş Huyugüzel, Pinar; Can, "Eğitimde sanal gerçeklik," TOJET: The Turkish Online, 3(4), 2004

[13] Ç. Erbaş and V. Demirer, "Eğitimde Artırılmış Gerçeklik Uygulamalar1: Google Glass Örneği 1,” Journal of Instructional Technologies \& Teacher Education, 3(2), 8-16, 2014.

[14] M. Billinghurst, H. Kato, and I. Poupyrev, "The MagicBook Moving seamlessly between reality and virtuality," IEEE Computer Graphics and Applications, 21(3), 6-8, 2001

[15] S. . Fleck, M. . Hachet, and J. M. . Christian Bastien, "Markerbased Augmented Reality: Instructional-design to improve children interactions with astronomical concepts," In Proceedings of IDC 2015: The 14th International Conference on Interaction Design and Children, 21-28, 2015.

[16] J.-C. Yen, C.-H. Tsai, and M. Wu, "Augmented Reality in the Higher Education: Students' Science Concept Learning and Academic Achievement in Astronomy," Procedia - Social and Behavioral Sciences, 103, 165-173, 2013.

[17] A. Taşkıran, E. Koral, and A. Bozkurt, "Artırılmış Gerçeklik Uygulamasının Yabancı Dil Öğretiminde Kullanılması," Akademik Biliş̧im, 462-467, 2015.

[18] Y. Özarslan, “Öğrenme ve Öğretmenin Genişletilmiş Gerçeklik ile Zenginleștirilmesi: OptikAR Uygulamas Enhancing Learning and Teaching with Augmented Reality: OptikAR Application," 5. International Computer And Instructional Technologies Symposium (ICITS 2011), 2011.

[19] E. İbili and S. Şahin, "Software Design and Development of an Interactive 3D Geometry Book Using Augmented Reality:ARGE3D," Afyon Kocatepe University Journal of Sciences and Engineering, 13(1), 1-8, 2013.

[20] R. Wojciechowski and W. Cellary, "Evaluation of learners' attitude toward learning in ARIES augmented reality environments," Computers and Education, 68, 570-585, 2013.

[21] H. Kaufmann and D. Schmalstieg, "Mathematics and geometry education with collaborative augmented reality," Computers and Graphics (Pergamon), 27(3), 339-345, 2003.

[22] H. Abdüsselam, Mustafa Serkan;Karal, "Fizik öğretiminde artırılmış gerçeklik ortamlarının öğrenci akademik başarıs üzerine etkisi: 11. Sinıf manyetizma konusu örneği," Eğitim ve Öğretim Araş̧tırmaları Dergisi, 1(4), 170-181, 2012.

[23] A. Bin Tomi and D. R. A. Rambli, "An interactive mobile augmented reality magical playbook: Learning number with the thirsty crow," Procedia Computer Science, 25, 123-130, 2003.

[24] L. Kerawalla, R. Luckin, S. Seljeflot, and A. Woolard, "'Making it real': exploring the potential of augmented reality for teaching primary school science," Virtual Reality, 10(3), $163-174,2006$.

[25] S. Somyürek, "Öğretim Sürecinde Z Kuşağının Dikkatini Çekme: Artırılmış Gerçeklik," Eğitim Teknolojisi Kuram ve Uygulama, 4(1), 63, 2014.

[26] Á. Di Serio, M. B. Ibáñez, and C. D. Kloos, "Impact of an augmented reality system on students' motivation for a visual art course," Computers and Education, 68, 585-596, 2013.

[27] W. Matcha and D. R. A. Rambli, "Exploratory study on collaborative interaction through the use of Augmented Reality in science learning," Procedia Computer Science, 25, 144-153, 2013.

[28] Ş. Kalaycı, SPSS Uygulamalı çok değişkenli istatistik teknikleri, 2009.

[29] S. Küçük, S. Kapakin, and Y. Göktaş, "Tıp Fakültesi Öğrencilerinin Mobil Artırılmış Gerçeklikle Anatomi Öğrenimine Yönelik Görüșleri,” Yükseköğretim ve Bilim Dergisi, 5(3), 316, 2015. 
[30] F. Davis, "Perceived usefulness, perceived ease of use, and user acceptance of information technology," MIS quarterly, 13(3), 319-340, 1989.

[31] F. D. Davis, R. P. Bagozzi, and P. R. Warshaw, "User acceptance of computer technology: a comparison of two theoretical models," Management Science, 35(8), 982-1003, 1989.

[32] M. Fishbein and I. Ajzen, "Belief, Attitude, Intention, and
Behavior: An Introduction to Theory and Research," Reading, MA: Addison-Wesley,1-18, 1975.

[33] A. Yıldırım and Ş. Hasan, Nitel Araştırma Yöntemler, Seçkin Yayıncılık, 2013.

[34] G. Ezgi, Artırılmış Gerçeklik Uygulamalarının Öğrencilerin Uzamsal Yeteneklerine Etkisi, Yüksek Lisans Tezi, Gazi Üniversitesi Eğitim Bilimleri Enstisüsü, 2014 